\title{
Memetic Computing Applied to the Design of Composite Materials and Structures
}

\author{
Jose Ignacio Pelaez, ${ }^{1,2}$ Jose Antonio Gomez-Ruiz,, \\ Jorge Veintimilla, ${ }^{3}$ Gustavo Vaccaro, ${ }^{2,4}$ and Patricia Witt ${ }^{4}$ \\ ${ }^{1}$ Department of Languages and Computer Sciences, University of Malaga, Malaga, Spain \\ ${ }^{2}$ Institute of Biomedical Research in Malaga (IBIMA), University of Malaga, Malaga, Spain \\ ${ }^{3}$ Department of Civil Engineering, Materials and Production, University of Malaga, Malaga, Spain \\ ${ }^{4}$ University of Guayaquil, Guayaquil, Ecuador
}

Correspondence should be addressed to Jose Antonio Gomez-Ruiz; janto@lcc.uma.es

Received 5 April 2017; Revised 30 July 2017; Accepted 16 August 2017; Published 28 September 2017

Academic Editor: David Greiner

Copyright (C) 2017 Jose Ignacio Pelaez et al. This is an open access article distributed under the Creative Commons Attribution License, which permits unrestricted use, distribution, and reproduction in any medium, provided the original work is properly cited.

\begin{abstract}
Presently, there exists an important need for lighter and more resistant structures, with reduced manufacturing costs. Laminated polymers are materials which respond to these new demands. Main difficulties of the design process of a composite laminate include the necessity to design both the geometry of the element and the material configuration itself and, therefore, the possibilities of creating composite materials are almost unlimited. Many techniques, ranging from linear programming or finite elements to computational intelligence, have been used to solve this type of problems. The aim of this work is to show that more effective and dynamic methods to solve this type of problems are obtained by using certain techniques based on systematic exploitation of knowledge of the problem, together with the combination of metaheuristics based on population as well as on local search. With this objective, a memetic algorithm has been designed and compared with the main heuristics used in the design of laminated polymers in different scenarios. All solutions obtained have been validated by the ANSYS ${ }^{\circledR}$ software package.
\end{abstract}

\section{Introduction}

A composite material is formed by the aggregation of two or more distinct materials to form a new one with enhanced properties: an agglomerate material known as the matrix and reinforcement materials that may be made up of continuous fibers, short fibers, or particles $[1,2]$. Well-designed material adopts the best properties of its constituents and even some that none of these possess. The aim of composite materials design is to generate new cheaper materials with improved strength and lightness. Not all of them can be improved simultaneously; therefore, the design objective is to obtain a new material that offers the best possible adaptation to the required specifications.

The exceptional strength and lightness of these materials have led to the development of a vast number of applications, particularly in the aeronautical and space industries due to the economic significance of these properties. Figure 1 shows the markets for composite materials.
Laminate is a particularly important type of composite material made up of laminas of the same composition with unidirectional reinforcement fibers, stacked, and bound together by the same material that forms the matrix, but with distinct fiber orientation. Within this category, symmetric laminates are worthy of special attention, with both geometrical and structural symmetry relative to the mid-plane.

One of the main difficulties of the design process of a laminate is to design both the geometry of the element and the material configuration itself as to best exploit the qualities of the constituent materials. Designing process must also evaluate the deterioration of the laminate properties over time due to stress, which can lead to unanticipated behaviour (cracks) or failure of the structural element in question.

Synthesis and analysis have been traditionally carried out using empirical knowledge based methods [3]. This is partly because the number of possible combinations of composites is almost unlimited and also because characterization by experimentation is very expensive. 


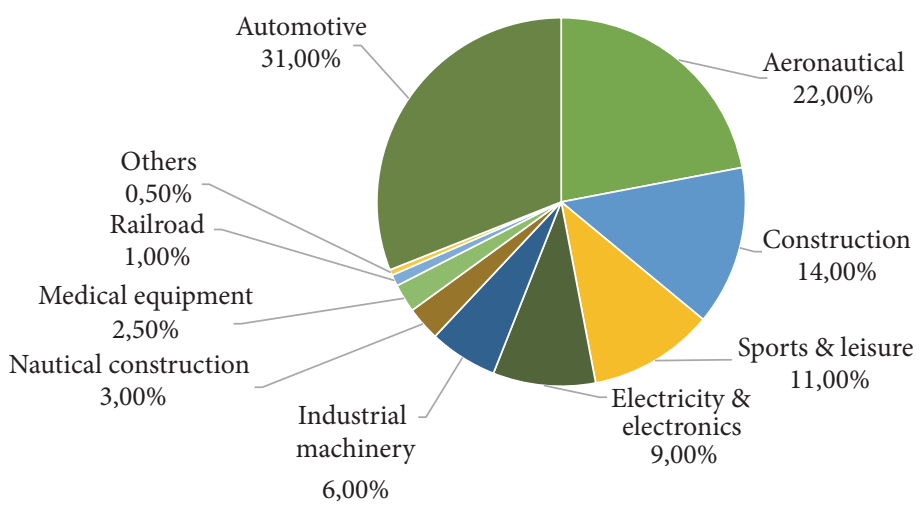

FIgURE 1: Markets for composite materials.

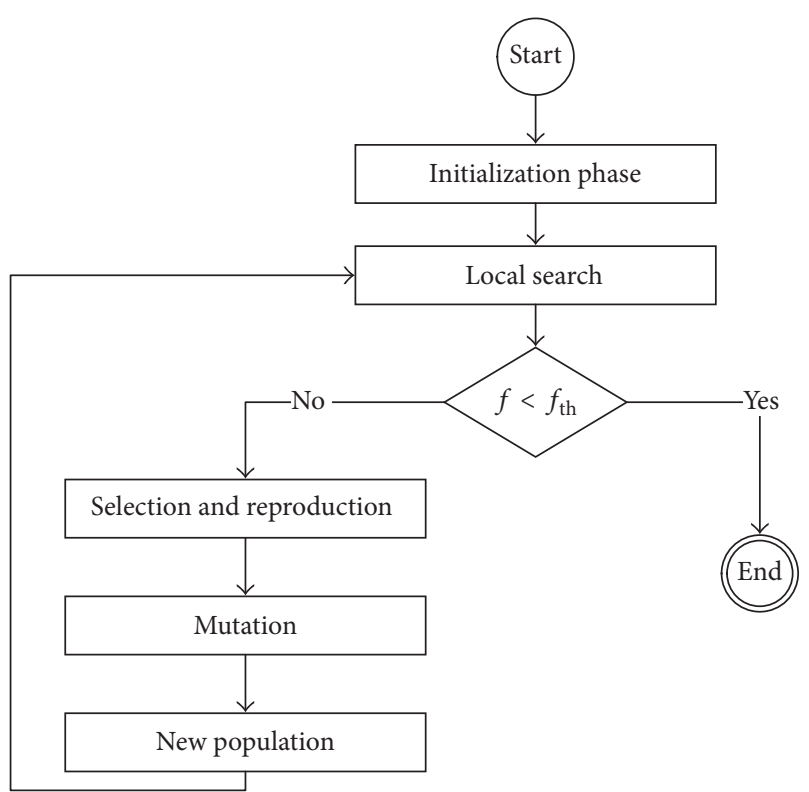

Figure 2: Scheme of the memetic algorithm. $f_{\text {th }}$ denotes a fixed threshold value used for the stopping criterion.

Since the 1990s, different design systems which aim to overcome these limitations have been proposed. These proposals have involved approaches ranging from traditional techniques such as classical nonlinear optimization procedures combined with finite element modelling $[4,5]$, through generic task methods and case-based reasoning [6], to modern artificial intelligence techniques [7-16].

Memetic Computing or Memetic Algorithms (MA) have proven to be efficient at numerous situations [17-21]. Figure 2 shows the scheme for a typical MA [22]. Local search is performed between each generation, in addition to the techniques used by Genetic Algorithms to explore the search space, namely, recombination/crossover and mutation. It is performed to improve the fitness of the population (in a localized region of the solution space) so that the next generation has "better" genes from its parents.
The aim of this work is to show that more effective and dynamic methods to solve problems of laminated polymers design are obtained by using certain techniques based on systematic exploitation of knowledge of the problem, together with the combination of metaheuristics based on population as well as on local search. With this objective, a MA has been designed and thoroughly compared with the main heuristics used in the design of laminated polymers in different scenarios. This work has been organized as follows: in Section 2, a studio of the main metaheuristics which have been used in the design of composite laminates is performed; in Section 3, a model for the design and optimization of symmetric laminates based on a MA is presented; in Section 4, this model is subjected to an exhaustive analysis and is compared with other methods to prove its usefulness; in Section 5, the MA-based model is applied to specific cases. Finally, conclusions are presented in Section 6.

\section{State of the Art of Composite Materials Design}

2.1. Genetic Algorithms. Genetic Algorithms (GA) have been the most popular method in the design of laminated polymers and optimizing piling sequence [23]. Callahan and Weeks [24], Nagendra et al. [25], Le Riche and Haftka [26], and Ball et al. [27] have been the first to adopt and use GA for the design of piling sequences of composite laminated materials. GA has also been used in problems with different objective functions, such as strength [28, 29], buckling loads [9, 28, 3034], dimensional stability [35], strain energy absorption [36], weight (either as a restriction or as an objective to minimize) $[37,38]$, bending/torsion connection, stiffness [36, 39], basic frequencies [34, 40-42], distortion [43], or finding laminate reference parameters [44].

GA have also been applied in the design of a variety of composite structures ranging from simple rectangular plates to complex geometrical sheets, such as sandwich panels [45], rigid sheets [46], bolt joints [47], and laminated cylindrical panels [34]. Similarly, GA have been combined with finite elements packages which analyse the response to tension and deformation of the composite material structure [43, 48, 49]. 
A combination of methods is sometimes used; for example, Park et al. [50] uses an approximate memory combined with a permutation operator and with the local learning/random mixture, in order to reduce function number and improve rate of convergence.

Some of the main problems regarding GA are deep computational necessity and premature convergence. In order to solve these drawbacks, increase the rate of convergence, reduce risk of premature convergence, and lessen function evaluation time, several modifications have been proposed, including the use of parallel computation [51, 52]; optimization of several levels (thick and thin level codification) [51]; introduction of problem-dependable operators [26]; layer adding or layer deleting, permutation, and interlaminar change $[9,46]$; generalized elitist and mutation of thickness of laminate/material/angle of fiber [49]; recovery of previously evaluated solutions [10, 50]; using approximation methods for the evaluation function [33, 53, 54]; training artificial neural network [34, 42]; initial blood-related population; or an aging hierarchic structure [55].

Sargent et al. [56] compared GA with some raging algorithms (i.e., random search, raging search, and simulated annealing) and observed that GA obtained better solutions than raging search, but in some cases they were unable to find a solution. Sivakumar et al. [57] compared David, Fletcher, and Powell (DFP)'s Quasi-Newton Method and GA, applied to reduce weight of a laminated composite limited by its basic frequencies. It was concluded that DFP converged in a reduced number of iterations when restriction number was small. However, finding a feasible number was difficult when restrictions number increased. Also considering that DFP could not handle discreet variables, it was concluded that "GA was a better tool to optimize laminated composites."

Even though GA has been widely used in optimization of piling sequence, an important flaw is its low rate of convergence. GA is an evolutionary algorithm based on population and might require several generations before converging into a solution [58]. Each generation consists of a great number of function evaluations; therefore, it could require plenty of computational time besides being very expensive.

2.2. Simulated Annealing. After Genetic Algorithms, simulated annealing (SA) is the second most popular method for the optimization of piling sequence in laminated composite materials [59-62].

The main problem of this technique is the generation of a sequence of points that converges into a nonoptimal solution. In order to solve this lack, some modifications have been proposed, such as an increase in the probability of sample points far from the present point [63] or the use of a set of points at a time instead of only one [64]. In order to increase the rate of convergence, Genovese et al. [65] proposed a two-level algorithm, including a "global annealing" in which all the design variables were disrupted simultaneously and a "local annealing" in which only one design variable was disrupted at a time. The local annealing was performed after each iteration of the global annealing in an attempt to improve the testing point locally. It was found that its speed of convergence was greater than the one-level simulated annealing and comparable with the optimization method based on gradient implemented by the Sequential Linear Programming (SLP) method.

SA is a good choice for the general case of optimal selection of laminate; however, it cannot be programmed to take benefit of the advantages of specific properties of a certain problem. GA is, in this respect, more flexible, but it frequently takes more computational time $[56,61,66]$. It is not easy to generalize the previous conclusion, since there are other researches, such as Rama Mohan Rao and Shyju [58], which shows that SA had better computational efficiency and was better at finding a solution to other combinatorial problems.

2.3. Tabu Search. Tabu Search (TS) was implemented by Pai et al. [14] for the optimization of piling sequence of laminates subjected to bulging and resistance requests as well as for matrix rupture. Results were compared with GA and they showed a comparative solution, but computational time depended on the case.

It has been used combined with other techniques, such as the SA. Rama Mohan Rao and Arvind [67] added a TS in the SA obtaining a method called tabu embedded in simulated annealing (TSA). Optimization of piling sequence of laminated composites was solved by the TSA, whilst restrictions are administrated through a correction strategy. TSA was faster than classic SA although more memory is required.

2.4. Variable Neighbourhood Search. Variable neighbourhood search (VNS) has been recently applied to laminated polymers design. Corz et al. [68] propose and compare an algorithm based on a variable environments search that allows the design of the geometry and composition of symmetric laminated composite materials. In this work, the implementation of the algorithm is shown in detail: objective function, encoding, fitness, neighbourhood structures, and local search, as well as the data used in the examples: volume fraction, efforts, and coefficients. The proposed model is compared with other techniques such as GA, SA, and TS, showing more efficient results.

\section{A Memetic Algorithm-Based Model for the Designing of Composite Materials}

In this section, the optimization problem, an encoding scheme for the representation of the problem, a fitness function to evaluate the feasibility of solutions, and the reproductive and local search operators used are presented.

3.1. Optimization Problem. The optimization problem can be formulated as follows: find the material (fiber $F$ and matrix $M)$, the volume fraction, $\mathrm{VF}$, and the laminate stacking sequence, $\theta_{1}, \ldots, \theta_{k}, \ldots, \theta_{n}$, with the purpose of maximizing the utilization of the laminate, thus achieving the lowest number of laminas $n$. The set of design variables is expressed as the vector $\widetilde{s}=\left(F, M, \mathrm{VF}, \theta_{1}, \ldots, \theta_{k}, \ldots, \theta_{n}\right)$. The degree of utilization of the laminate material is defined as a positive real number that is obtained from the fitness function $(\mathrm{FF})$, 
TABLE 1: Encoding used for a laminate.

\begin{tabular}{|c|c|c|c|c|c|c|c|c|c|c|c|}
\hline \multirow{4}{*}{$\begin{array}{l}\text { IU } \\
\text { Fiber }\end{array}$} & \multicolumn{11}{|c|}{ Values } \\
\hline & \multicolumn{11}{|c|}{ A set of eleven fibres are used, each represented by an integer number } \\
\hline & 1 & 2 & 3 & 4 & 5 & 6 & 7 & 8 & 9 & 10 & 11 \\
\hline & E-Glass & S-Glass & AS-1 & AS-4 & IM-7 & P-100 & $\mathrm{T}-40$ & $\mathrm{~T}-300$ & Boron & Kevlar-49 & Kevlar-149 \\
\hline \multirow{3}{*}{ Matrix } & \multicolumn{11}{|c|}{ A set of five matrices are used, each represented by an integer number } \\
\hline & \multicolumn{2}{|c|}{1} & \multicolumn{2}{|c|}{2} & \multicolumn{3}{|c|}{3} & \multicolumn{2}{|c|}{4} & \multicolumn{2}{|l|}{5} \\
\hline & \multicolumn{2}{|c|}{ Peek } & & & \multicolumn{2}{|c|}{ Polyester } & \multicolumn{3}{|c|}{ Epoxy } & Polyamide & \\
\hline Volume fraction & \multicolumn{11}{|c|}{ A real number from the set $\{0.3,0.4,0.5,0.6,0.7\}$} \\
\hline Geometry of the laminate & \multicolumn{11}{|c|}{ A sequence of integers, one for each lamina, in the range $\left[-80^{\circ},+90^{\circ}\right]$, in $10^{\circ}$ intervals } \\
\hline
\end{tabular}

\begin{tabular}{|c|c|c|c|c|}
\hline Fibre & Matrix & Volume fraction & Geometry & \multirow[t]{2}{*}{ Fitness } \\
\hline IU 1 & IU 2 & IU 3 & IU 4 & \\
\hline
\end{tabular}

FIGURE 3: Structure of the laminate.

defined in the Section 3.2, to the $\widetilde{s}$ vector. Therefore, the optimization problem and its corresponding constrains can be defined as follows:

$$
\max (\mathrm{FF}(\widetilde{s}))
$$

where

$$
n \geq 2 \text { (number of laminas); }
$$

$\mathrm{VF} \in[0.3,0.7]$ in 0.1 intervals (volume fraction);

$\theta_{i} \in\left[-80^{\circ}, 90^{\circ}\right]$ in $10^{\circ}$ intervals (orientation of the laminas).

3.2. Encoding. The structure of the laminate will be represented by an agent formed by four information units (IU), which encode the fiber, the matrix, the volume fraction, and the laminate geometry (see Figure 3). Fitness, that shows how well adapted the solution is to its environment, is added to the structure.

Each of the four IU that define the laminate represents a different characteristic of its composition: fiber and matrix are represented by an integer number; volume fraction is represented by a real number; and geometry is represented by a sequence of integers that represent the direction of fibers. The values used for the different IU are shown in Table 1.

To represent the geometry of the laminate, we use the following notation: $[50 /-10 / 0 / 60 /-20]_{s}$. It is a symmetric laminate whose outer (first) lamina has an orientation of $50^{\circ}$, the second one (next) of $-10^{\circ}$, and so on. A simplified representation of a symmetric laminate is shown in Figure 4.

Different failure criteria can be used to determine whether a lamina can withstand specific stress conditions without breaking [1]. In this article, the Tsai-Wu failure criteria [69] have been selected. In order to determine if a

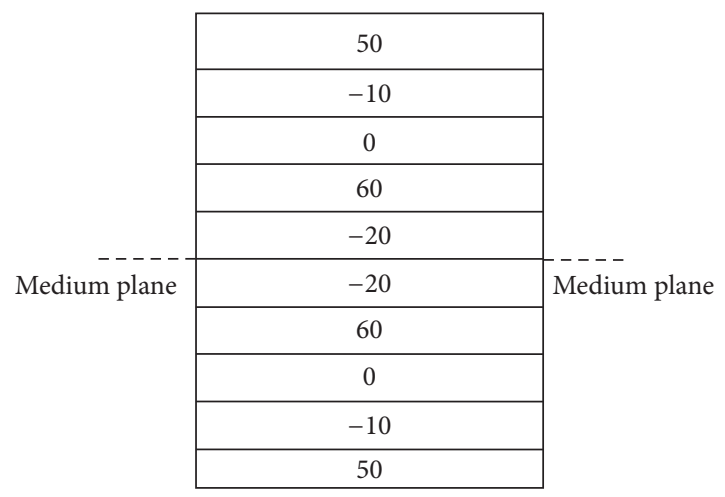

FIGURE 4: Symmetric laminate.

lamina breaks, for each lamina $i$ of a laminate, its Tsai-Wu coefficient $P_{k}^{i}$ is defined as

$$
\begin{aligned}
P_{k}^{i}= & \left(\frac{1}{X}-\frac{1}{X^{\prime}}\right) \cdot \sigma_{1}+\left(\frac{1}{Y}-\frac{1}{Y^{\prime}}\right) \cdot \sigma_{2}+\frac{1}{X \cdot X^{\prime}} \cdot \sigma_{1}^{2} \\
& +\frac{1}{Y \cdot Y^{\prime}} \cdot \sigma_{2}^{2}-\sqrt{\frac{1}{X \cdot X^{\prime} \cdot Y \cdot Y^{\prime}}} \cdot \sigma_{1} \cdot \sigma_{2}+\frac{1}{S^{2}} \\
& \cdot \tau_{12}^{2},
\end{aligned}
$$

where $X, X^{\prime}, Y, Y^{\prime}$, and $S$ are, respectively, the ultimate tensile and compressive strength in the fiber direction, the ultimate tensile and compressive transversal strength, and the shear strength. $\sigma_{1}$ and $\sigma_{2}$ are the stress resistance coefficients for the $x$-and $y$-axes, respectively, and $\tau_{12}$ is the stress coefficient of an orthotropic lamina under plane stress conditions. Applying the Tsai-Wu failure criteria [69], the lamina does not break if $P_{k}^{i} \leq 1, \forall i$, and breaks otherwise. Furthermore, if $P_{k}^{i} \cong 1$, the lamina $i$ is working at full capacity. If a lamina is broken, then the entire laminate is discarded.

3.3. Fitness. The fitness function considers economic and safety criteria, so the alignment of stresses along the direction of the fibers is improved and the following are penalized: volume fraction and high laminate thickness; stacking more than four consecutive laminas with the same fiber orientation; the distribution of stress in directions other than that 
TABLE 2: Fitness equation coefficients.

\begin{tabular}{|c|c|}
\hline Coefficient & Description \\
\hline$P_{1}$ & $\begin{array}{l}\text { Longitudinal coefficient along the direction of the fibres. It is a real value indicating the relationship between } \\
\text { longitudinal stress in the direction of the fibres and the breakage stress in that direction. As the direction of the fibres } \\
\text { is that of most resistance, it is of interest that this ratio is as high as possible. For this reason, it is in the numerator. } \beta \\
\text { has been empirically determined as } 2 \text {. } \\
P_{1}=\sum_{i}\left(\left|\sigma_{1}^{i} / X^{i}\right| \vee\left|\sigma_{1}^{i} / X^{\prime i}\right|\right) \text { where the stress } \sigma_{1}^{i} \text { is either tensile or compressive and the sum applies to the laminas that } \\
\text { do not break. }\end{array}$ \\
\hline$P_{2}$ & $\begin{array}{l}\text { Longitudinal coefficient perpendicular to the direction of the fibres. It is a real value that indicates the relationship } \\
\text { between the longitudinal stress perpendicular to the fibres and the breakage stress in that direction. As the direction } \\
\text { which is perpendicular to the fibres is that of least resistance, it is of interest that this ratio is as small as possible. For } \\
\text { this reason it is in the denominator. } \\
P_{2}=\sum_{i}\left(\left|\sigma_{2}^{i} / Y^{i}\right| \vee\left|\sigma_{2}^{i} / Y^{\prime i}\right|\right) \text { where the stress } \sigma_{2}^{i} \text { is either tensile or compressive and the sum applies to all the laminas. }\end{array}$ \\
\hline$P_{12}$ & $\begin{array}{l}\text { Shear coefficient. It is a real value that indicates the relationship between the shear stress in the plane and the } \\
\text { maximum stress that can be tolerated in that plane. As the lamina has low resistance to these stresses, it is of interest } \\
\text { that this ratio is as small as possible. For this reason it is in the denominator. The sum applies to all the laminas. } \\
P_{12}=\sum_{i}\left|\tau_{12}^{i} / S^{i}\right|\end{array}$ \\
\hline CLA & $\begin{array}{l}\text { Coefficient that indicates whether the number of adjacent layers with the same orientation is less than or equal to four } \\
(\mathrm{CLA}=0) \text { or greater than four }\left(\mathrm{CLA}=10^{10}\right) \text { It is in the denominator so as to heavily penalize this second possibility. } \\
\text { Its values have been empirically determined. }\end{array}$ \\
\hline VF & $\begin{array}{l}\text { Fiber volume fraction of the laminate. As this value should tend towards small values that are more advantageous } \\
\text { economically, it is placed in the denominator where small values will have a positive effect. }\end{array}$ \\
\hline$n \cdot e$ & Product of the number of laminas and its thickness (expressed in metres). $\gamma$ has been empirically determined as 12. \\
\hline$R$ & $\begin{array}{l}\text { It indicates the number of layers that break }\left(P_{k}^{i}>1\right) \text {, and is in the denominator in order to penalize such event. } \delta \text { has } \\
\text { been empirically determined as } 4 .\end{array}$ \\
\hline
\end{tabular}

of the fibers; and lamina breakage. A higher value indicates a better solution. The fitness function, FF, is defined as

$$
\begin{aligned}
\mathrm{FF} & =10^{\alpha} \\
\cdot & \frac{P_{1}^{\beta}}{(\mathrm{CLA}+1) \cdot \mathrm{VF} \cdot(n \cdot e)^{\gamma} \cdot(R+1)^{\delta} \cdot\left(P_{2}+1\right) \cdot\left(P_{12}+1\right)},
\end{aligned}
$$

where the coefficients are described in Table 2. The multiplicative factor $10^{\propto}$ is to maintain fitness values between manageable values. $\alpha$ has been empirically determined as -28 .

3.4. Reproductive Operator. Crossover operator is different for each IU In case of fiber, matrix, and volume fraction IU, a classic one-point crossover operator adapted to the different possible cases is used. However, for geometry IU, the classic crossover operator is not used because it is very static in changing the number of layers. To avoid this problem, a dynamic crossover operator with a different crossover point for each parent is proposed. Such crossover points are determined by generating two integer numbers from a continuous uniform distribution. The first number lies between 0 and the number of laminas of the first laminate, $l_{1}$, and the second between 1 and the number of laminas of the second laminate, $l_{2}$, plus 1 . Then, the parent laminates are split into two parts, with the child joining together the left part of the first parent and the right part of the second parent being formed. Depending on the location of these crossover points, $p_{1}$ and $p_{2}$ can be obtained different cases shown in Table 3.
3.5. Local Search Operators. A set of local search operators are defined, following previous applications of a variable neighbourhood search-based model [68]. These operators allow a lamina to be added or removed, to change its orientation, type of matrix, and type of fiber or volume fraction. Two new operators have been defined in order to better exploit the region being explored in a given time. The operators proposed in the model are summarized in Table 4.

3.6. Implementation. The MA proposed model is compared with other heuristics in order to verify its advantages. These heuristics (detailed in Section 2) are GA, VNS, SA, and TS. All heuristics use the same representation of the problem proposed in this paper. Experiments were performed in the Picasso Computer at University of Malaga (512 IBM PowerPC 970 processors, 2994.04 GFlops).

In Tables 5 and 6, characteristics of the materials (fibers and matrices) used in the tests for the laminates design are shown.

\section{Experiments and Results}

The problem is to determine the composition and thickness of a laminated plate under a distributed $N_{x}$ and $N_{y}$ loading. Table 7 presents the statistics for 21 different loading cases $(n=21)$ and the 5 heuristics $(k=5)$ indicated in Section 3.6, with 500 simulations each. For each model, the results shown correspond to the smallest number of laminas of the material obtained, $\mathrm{NL}_{\text {min }}$, the number of times this smallest number is 
TABLE 3: Different cases for crossover operator.

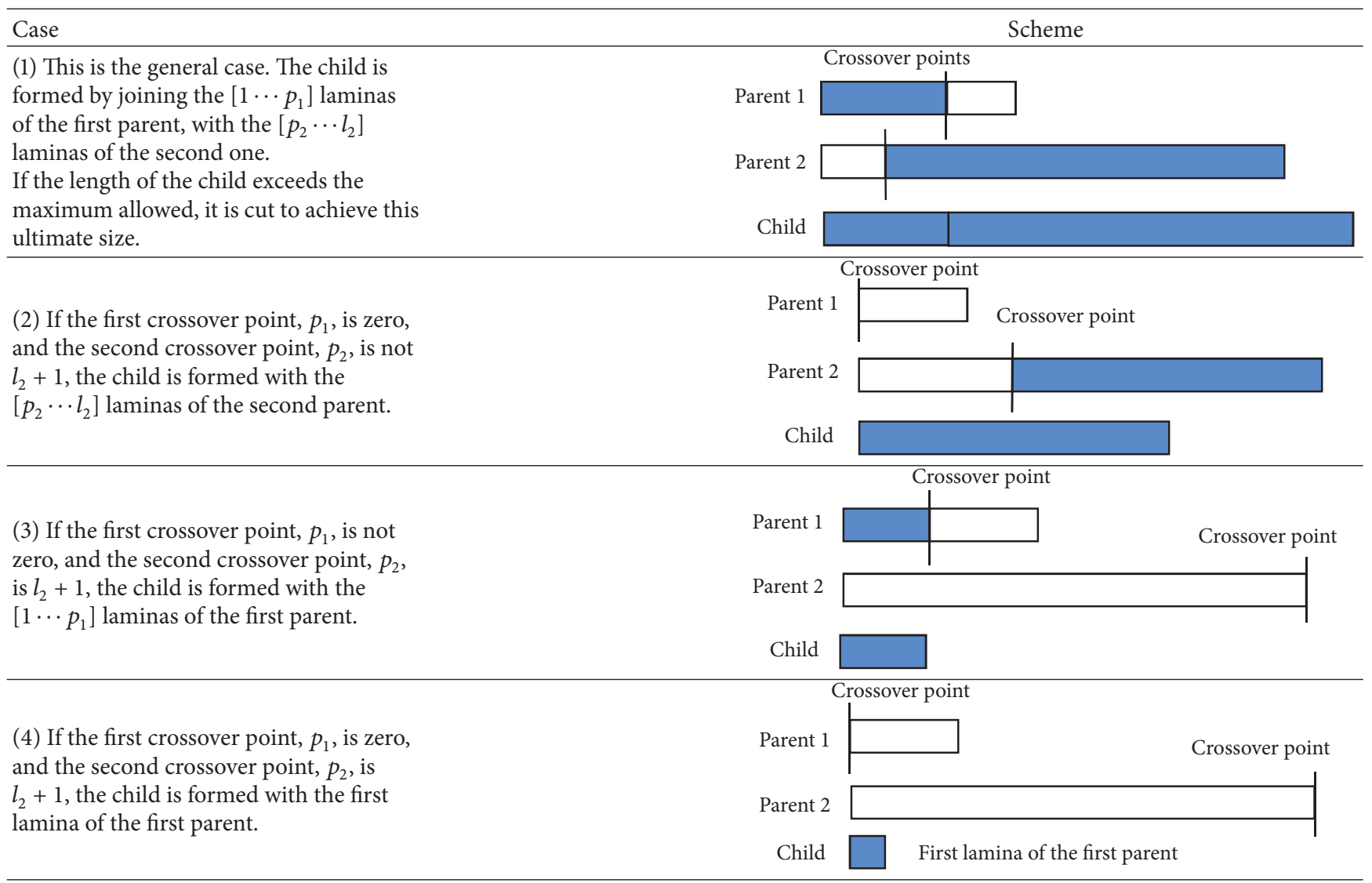

obtained, NL, and its average $\overline{\mathrm{NL}}$. Also, the best (maximum) fitness obtained, $\mathrm{FF}_{\max }$, and its average $\overline{\mathrm{FF}}$ are presented.

4.1. Statistical Significance Test. In order to explore the result of simulations a statistical significance test is applied. The choice of test depends upon what it is intended to study, as Demšar [70] showed that nonparametric tests are safer and more appropriate than parametric tests for comparisons between two or more algorithms on multiple data sets.

A null or no-effect hypothesis is to be formulated prior to the application of the test. It often supports the equality or absence of differences among the results of the algorithms and enables alternative hypotheses to be raised that support the opposite [71]. The null hypothesis can be represented by $H_{0}$ and the alternative hypothesis by $H_{a}$. The application of the tests leads to the computation of a statistic, which can be used to reject the null hypothesis at a given level of significance $\alpha$. It is also possible to compute the smallest level of significance that results in the rejection of the null hypothesis. This level is the $p$ value, which is the probability of obtaining a result at least as extreme as the one that was actually observed, assuming that the null hypothesis is true. The use of $p$ values is often preferred over using only fixed $\alpha$ levels since they provide cleaner measures of how significant the result is (the smaller the $p$-value, the stronger the evidence against the null hypothesis is) [72].
The Friedman test $[73,74]$ is a nonparametric test with multiple comparisons that aims to detect significant differences between the behaviour of two or more algorithms. The null hypothesis for Friedman's test states equality of medians between the populations. The alternative hypothesis is defined as the negation of the null hypothesis, so it is nondirectional. The first step in calculating the test statistic is to convert the original results to ranks. They are computed using the following procedure ( $n$ is the number of problems considered where $i$ is its associated index and $k$ is the number of algorithms included in the comparison where $j$ is its associated index):

(1) Gather observed results for each algorithm/problem pair.

(2) For each problem $i$, rank values from 1 (best result) to $k$ (worst result). Denote these ranks as $r_{i}^{j}(1 \leq j \leq k)$.

(3) For each algorithm $j$, average the ranks obtained in all problems to obtain the final rank $R_{j}=(1 / n) \sum_{i} r_{i}^{j}$.

Thus, it ranks the algorithms for each problem separately; the best performing algorithm should have the rank of 1 , the second best rank 2, and so forth. Under the null hypothesis, 
TABLE 4: Local search operators.

\begin{tabular}{|c|c|c|}
\hline Operator & Description & Function \\
\hline Number 1 & $\begin{array}{l}\text { It operates on the geometry IU of the laminate, varying the } \\
\text { orientation of the laminas, moving each of them } 10^{\circ} \text { closer to } \\
0^{\circ} \text {. If the orientation of a lamina is } 0^{\circ} \text {, it is left unchanged. }\end{array}$ & $\begin{array}{l}\text { To obtain solutions with improved } \\
\text { longitudinal stress tolerance along the } \\
x \text {-axis better. }\end{array}$ \\
\hline Number 2 & $\begin{array}{l}\text { It operates on the geometry IU of the laminate, varying the } \\
\text { orientation of the laminas, moving each of them } 10^{\circ} \text { closer to } \\
90^{\circ} \text {. If the orientation of a lamina is } 90^{\circ} \text {, it is left unchanged, } \\
\text { and if it is }-80^{\circ} \text { it is changed to } 90^{\circ} \text {. }\end{array}$ & $\begin{array}{l}\text { To obtain solutions with improved } \\
\text { longitudinal stress tolerance along the } \\
y \text {-axis better. }\end{array}$ \\
\hline Number 3 & $\begin{array}{l}\text { It operates on the geometry IU of the laminate, varying the } \\
\text { orientation of the laminas, moving each of them } 10^{\circ} \text { closer to } \\
+45^{\circ} \text { or }-45^{\circ} \text {, depending on whether it is positive or negative. } \\
\text { If the orientation of a lamina is } 40^{\circ}, 50^{\circ},-40^{\circ} \text { or }-50^{\circ} \text {, it is left } \\
\text { unchanged, and if it is } 0^{\circ} \text { it is changed to } 10^{\circ} \text {. }\end{array}$ & $\begin{array}{l}\text { To obtain solutions with improved shear } \\
\text { stress tolerance. }\end{array}$ \\
\hline Number 4 & $\begin{array}{l}\text { It operates on the geometry IU of the laminate, adding an } \\
\text { individual lamina with random orientation and positioning. } \\
\text { If the number of laminas is already the maximum possible, it } \\
\text { is left unchanged. }\end{array}$ & $\begin{array}{l}\text { To explore into the direction of the } \\
\text { greatest number of laminas }\end{array}$ \\
\hline Number 5 & $\begin{array}{l}\text { It operates on the geometry I.U. of the laminate, removing an } \\
\text { individual lamina, chosen at random. If there is only one } \\
\text { lamina, it is left unchanged. }\end{array}$ & $\begin{array}{l}\text { To explore into the direction of the least } \\
\text { number of laminas }\end{array}$ \\
\hline Number 6 & $\begin{array}{l}\text { It operates on the geometry IU of the laminate, changing the } \\
\text { orientation of a lamina, chosen at random and relocated in a } \\
\text { new position, also chosen at random. }\end{array}$ & $\begin{array}{l}\text { To explore into the direction of new } \\
\text { orientations. }\end{array}$ \\
\hline Number 7 & $\begin{array}{l}\text { It operates on the fiber IU, changing it by a distinct one, } \\
\text { chosen at random, maintaining the matrix, the volume } \\
\text { fraction, the number of laminas and their orientation } \\
\text { constant. }\end{array}$ & $\begin{array}{l}\text { To explore into the subspace solution of } \\
\text { the fibres alone. }\end{array}$ \\
\hline Number 8 & $\begin{array}{l}\text { It operates on the matrix I.U., changing it by a distinct one, } \\
\text { chosen at random, maintaining the fiber, the volume fraction, } \\
\text { the number of laminas and their orientation constant. }\end{array}$ & $\begin{array}{l}\text { To explore into the subspace solution of } \\
\text { the matrices alone. }\end{array}$ \\
\hline Number 9 & $\begin{array}{l}\text { It operates on the volume fraction IU, changing its value for a } \\
\text { distinct one, chosen at random, within the acceptable limits, } \\
\text { maintaining the fiber, the matrix, the number of laminas and } \\
\text { their orientation constant. }\end{array}$ & $\begin{array}{l}\text { To explore into the subspace solution of } \\
\text { the volume fraction alone. }\end{array}$ \\
\hline Number 10 & $\begin{array}{l}\text { It operates on the geometry IU of the laminate, adding an } \\
\text { individual lamina with orientation of }-10^{\circ} \text { from the last } \\
\text { positioned lamina. If the number of laminas is already the } \\
\text { maximum possible, it is left unchanged. }\end{array}$ & $\begin{array}{l}\text { To explore into the greatest number of } \\
\text { laminas. }\end{array}$ \\
\hline Number 11 & $\begin{array}{l}\text { It operates on the geometry IU of the laminate, removing an } \\
\text { individual lamina, the closest to the last removed lamina, } \\
\text { with different angular orientation. If there is only one lamina, } \\
\text { it is left unchanged. }\end{array}$ & $\begin{array}{l}\text { To explore into the smallest number of } \\
\text { laminas. }\end{array}$ \\
\hline
\end{tabular}

which states that all the algorithms behave similarly (therefore their ranks $R_{j}$ should be equal), the Friedman statistic $F_{f}$ can be computed as

$$
F_{f}=\frac{12 n}{k(k+1)}\left[\left(\sum_{j} R_{j}^{2}\right)-\frac{k(k+1)^{2}}{4}\right]
$$

which is distributed according to a chi-square distribution with $(k-1)$ degrees of freedom.
Iman and Davenport [75] derived a less conservative alternative with statistic distributed according to following $F$ distribution with $(k-1)$ and $(k-1)(n-1)$ degrees of freedom:

$$
F_{\mathrm{ID}}=\frac{(n-1) \chi_{F}^{2}}{n(k-1)-\chi_{F}^{2}} \text {. }
$$

Table 8 depicts the rank computed through the Friedman test for all heuristics considered in the exhaustive analysis (in our case of study $n=21$ and $k=5$ ) according to the average fitness, $\bar{F}$, of each distributed $N_{x}$ and $N_{y}$ loading. As can be deduced from Table 8 , MA with a rank of 1 is the best 
TABLE 5: Characteristics of fibers used in the design process.

\begin{tabular}{|c|c|c|c|}
\hline Material & Module elastic $E[\mathrm{GPa}]$ & Resistance traction $\sigma_{f}[\mathrm{MPa}]$ & Coefficient Poisson $v$ \\
\hline \multicolumn{4}{|l|}{ Glass fiber } \\
\hline E-Glass & 72.40 & 3450.00 & 0.20 \\
\hline S_Glass & 86.90 & 4300.00 & 0.22 \\
\hline \multicolumn{4}{|l|}{ Carbon fiber } \\
\hline AS-1 & 228.00 & 3100.00 & 0.20 \\
\hline AS-4 & 248.00 & 4070.00 & 0.20 \\
\hline IM-7 & 301.00 & 5310.00 & 0.20 \\
\hline P-100 & 758.00 & 2410.00 & 0.20 \\
\hline $\mathrm{T}-40$ & 290.00 & 5650.00 & 0.20 \\
\hline $\mathrm{T}-300$ & 231.00 & 3650.00 & 0.20 \\
\hline \multicolumn{4}{|l|}{ Boron fiber } \\
\hline Boron & 393.00 & 3100.00 & 0.20 \\
\hline \multicolumn{4}{|l|}{ Aramid fiber } \\
\hline Kevlar 49 & 131.00 & 3620.00 & 0.35 \\
\hline Kevlar 149 & 179.00 & 3450.00 & 0.35 \\
\hline Material & $\begin{array}{c}\text { Module elastic } \\
E[\mathrm{GPa}]\end{array}$ & $\begin{array}{c}\text { Resistance } \\
\text { traction } \\
\sigma_{f}[\mathrm{MPa}]\end{array}$ & $\begin{array}{l}\text { Coefficient } \\
\text { Poisson } v\end{array}$ \\
\hline \multicolumn{4}{|c|}{ Thermoplastics } \\
\hline Peek & 3.24 & 100.00 & 0.40 \\
\hline PPS & 3.30 & 82.70 & 0.33 \\
\hline \multicolumn{4}{|c|}{ Thermostables } \\
\hline Polyester & 3.00 & 50.00 & 0.30 \\
\hline Epoxy resin & 4.60 & 58.60 & 0.36 \\
\hline Polyamide & 3.50 & 103.00 & 0.35 \\
\hline
\end{tabular}

performing algorithm, whereas SA with a rank of 4.948 is the worst.

The Friedman statistic computed by (4) (distributed according to chi-square with 4 degrees of freedom) is 82.552381 and its $p$ value is $8.256673 e-11$ and the ImanDavenport extension computed by (5) (distributed according to $F$-distribution with 4 and 80 degrees of freedom) is 1140.526316 and its $p$ value is $1.149264 e-69$. In both cases, the $p$ value is less than the significance level $\alpha=0.05$; and $H_{0}$ for which there is no difference in rankings for these 5 heuristics is rejected.

Rejection of $H_{0}$ must be followed by a post hoc procedure to characterize the differences between algorithms. The aim of the application of post hoc procedures is to perform a comparison considering a control method and a set of algorithms. A family of hypotheses can be defined, all related to the control method. Then, the application of a post hoc test can lead to obtaining a $p$ value which determines the degree of rejection of each hypothesis [76]. A family of hypotheses is a set of logically interrelated hypotheses of comparisons which, in $(1 \times n)$ comparisons, compares the $(k-1)$ algorithms of the study (excluding the control) with the control method, whereas, in $(n \times n)$ comparisons, it considers the $(k(k-1) / 2)$ possible comparisons among algorithms. Therefore, the family will be composed of $(k-1)$ or $(k(k-1) / 2)$ hypotheses, respectively, which can be ordered by its $p$ value, from lowest to highest.

In our comparison, the appropriated post hoc procedure is the Nemenyi test [77] because multiple algorithms on multiple data sets are compared. In our case of study $(n=$ 21 and $k=5)$ there are 10 hypotheses for $(5 \times 4) / 2$ possible comparisons among algorithms. The $p$ values for the Nemenyi test are shown in Table 9 ordered by $p$ values, where in each row the first heuristic has better (lower) average ranking than the second. If the corresponding $p$ value is smaller than $\alpha=0.05$, then the first heuristic is significantly better than the second ( $H_{0}$ hypothesis rejected).

As can be deduced from Table 9, the MA proposed model significantly performs better than the others because the $H_{0}$ hypothesis is rejected in all comparative pairs.

4.2. Analysis of Results. As indicated in Section 4.1, the MA proposed model is significantly better than the others heuristics respect to the fitness function. Moreover, in many cases, the proposed model obtains a material with the lowest number of layers and such occurrences are greater than the 
TABLE 7: Statistics corresponding to the series of simulations. Biaxial loading $N_{x}: N_{y}$.

\begin{tabular}{|c|c|c|c|c|c|c|}
\hline Loads & Algorithm & $\mathrm{NL}_{\min }$ & NL & $\overline{\mathrm{NL}}$ & $\mathrm{FF}_{\max }$ & $\overline{\mathrm{FF}}$ \\
\hline \multirow{5}{*}{$\begin{array}{l}N_{x}: 250.000 \mathrm{~N} / \mathrm{m} \\
N_{y}: 250.000 \mathrm{~N} / \mathrm{m}\end{array}$} & VNS & 6 & 500 & 6 & $2.8594 \cdot 10^{8}$ & $2.7272 \cdot 10^{8}$ \\
\hline & MA & 6 & 500 & 6 & $2.8594 \cdot 10^{8}$ & $2.8594 \cdot 10^{8}$ \\
\hline & $\mathrm{AG}$ & 6 & 89 & 8.28 & $2.8594 \cdot 10^{8}$ & $6.969 \cdot 10^{7}$ \\
\hline & SA & 8 & 76 & 12.456 & $8.978 \cdot 10^{6}$ & $1.1579 \cdot 10^{5}$ \\
\hline & TS & 6 & 32 & 8.7120 & $2.7920 \cdot 10^{8}$ & $7.4150 \cdot 10^{6}$ \\
\hline \multirow{5}{*}{$\begin{array}{l}N_{x}: 250.000 \mathrm{~N} / \mathrm{m} \\
N_{y}: 500.000 \mathrm{~N} / \mathrm{m}\end{array}$} & VNS & 8 & 500 & 8 & $1.4029 \cdot 10^{7}$ & $1.2698 \cdot 10^{7}$ \\
\hline & MA & 8 & 500 & 8 & $1.4029 \cdot 10^{7}$ & $1.3822 \cdot 10^{7}$ \\
\hline & AG & 8 & 35 & 11.8 & $1.3145 \cdot 10^{7}$ & $1.2643 \cdot 10^{6}$ \\
\hline & SA & 8 & 10 & 16.544 & $5.6258 \cdot 10^{6}$ & $2.0485 \cdot 10^{4}$ \\
\hline & TS & 8 & 13 & 10.5680 & $1.0056 \cdot 10^{7}$ & $1.5439 \cdot 10^{5}$ \\
\hline \multirow{5}{*}{$\begin{array}{l}N_{x}: 250.000 \mathrm{~N} / \mathrm{m} \\
N_{y}: 750.000 \mathrm{~N} / \mathrm{m}\end{array}$} & VNS & 8 & 498 & 8.008 & $6.6161 \cdot 10^{6}$ & $6.3187 \cdot 10^{6}$ \\
\hline & MA & 8 & 500 & 8 & $6.6161 \cdot 10^{6}$ & $6.6044 \cdot 10^{6}$ \\
\hline & AG & 8 & 3 & 14.4733 & $6.5042 \cdot 10^{6}$ & $1.9654 \cdot 10^{5}$ \\
\hline & SA & 10 & 26 & 19.532 & $4.3045 \cdot 10^{5}$ & $3.4465 \cdot 10^{3}$ \\
\hline & $\mathrm{TS}$ & 8 & 3 & 11.5360 & $5.2699 \cdot 10^{6}$ & $3.5922 \cdot 10^{4}$ \\
\hline \multirow{5}{*}{$\begin{array}{l}N_{x}: 250.000 \mathrm{~N} / \mathrm{m} \\
N_{y}: 1.000 .000 \mathrm{~N} / \mathrm{m}\end{array}$} & VNS & 8 & 471 & 8.116 & $8.2968 \cdot 10^{6}$ & $5.4898 \cdot 10^{6}$ \\
\hline & MA & 8 & 500 & 8 & $8.2968 \cdot 10^{6}$ & $8.2815 \cdot 10^{6}$ \\
\hline & $\mathrm{AG}$ & 10 & 18 & 17.1267 & $7.6349 \cdot 10^{5}$ & $6.3974 \cdot 10^{4}$ \\
\hline & SA & 10 & 24 & 21.12 & $6.7663 \cdot 10^{5}$ & $2.5123 \cdot 10^{3}$ \\
\hline & TS & 10 & 3 & 12.4680 & $5.0663 \cdot 10^{5}$ & $5.1883 \cdot 10^{3}$ \\
\hline \multirow{5}{*}{$\begin{array}{l}N_{x}: 250.000 \mathrm{~N} / \mathrm{m} \\
N_{y}: 1.250 .000 \mathrm{~N} / \mathrm{m}\end{array}$} & VNS & 8 & 118 & 9.528 & $6.6895 \cdot 10^{6}$ & $1.866 \cdot 10^{6}$ \\
\hline & MA & 8 & 500 & 8 & $6.6895 \cdot 10^{6}$ & $6.0696 \cdot 10^{6}$ \\
\hline & AG & 10 & 2 & 20.52 & $1.0673 \cdot 10^{6}$ & $1.9896 \cdot 10^{4}$ \\
\hline & SA & 12 & 3 & 23.672 & $4.5062 \cdot 10^{4}$ & $3.2251 \cdot 10^{2}$ \\
\hline & TS & 10 & 1 & 13.6400 & $5.9026 \cdot 10^{5}$ & $3.0134 \cdot 10^{3}$ \\
\hline \multirow{5}{*}{$\begin{array}{l}N_{x}: 250.000 \mathrm{~N} / \mathrm{m} \\
N_{y}: 1.500 .000 \mathrm{~N} / \mathrm{m}\end{array}$} & VNS & 10 & 496 & 10.016 & $9.0479 \cdot 10^{5}$ & $6.8493 \cdot 10^{5}$ \\
\hline & MA & 10 & 500 & 10 & $9.0479 \cdot 10^{5}$ & $8.9861 \cdot 10^{5}$ \\
\hline & AG & 12 & 14 & 24.26 & $2.8056 \cdot 10^{5}$ & $9.3622 \cdot 10^{3}$ \\
\hline & SA & 10 & 22 & 26.24 & $5.6722 \cdot 10^{5}$ & $2.4689 \cdot 10^{3}$ \\
\hline & TS & 12 & 4 & 14.7000 & $8.7860 \cdot 10^{4}$ & $1.0494 \cdot 10^{3}$ \\
\hline \multirow{5}{*}{$\begin{array}{l}N_{x}: 500.000 \mathrm{~N} / \mathrm{m} \\
N_{y}: 500.000 \mathrm{~N} / \mathrm{m}\end{array}$} & VNS & 10 & 400 & 10.4 & $6.37 \cdot 10^{5}$ & $5.0705 \cdot 10^{5}$ \\
\hline & MA & 10 & 481 & 10.08 & $6.37 \cdot 10^{5}$ & $6.1494 \cdot 10^{5}$ \\
\hline & $\mathrm{AG}$ & 10 & 3 & 15.6467 & $5.6117 \cdot 10^{5}$ & $6.2101 \cdot 10^{4}$ \\
\hline & SA & 12 & 4 & 21.292 & $1.5327 \cdot 10^{5}$ & $1.1971 \cdot 10^{3}$ \\
\hline & TS & 10 & 3 & 13.9240 & $5.6117 \cdot 10^{5}$ & $1.0223 \cdot 10^{4}$ \\
\hline \multirow{5}{*}{$\begin{array}{l}N_{x}: 500.000 \mathrm{~N} / \mathrm{m} \\
N_{y}: 750.000 \mathrm{~N} / \mathrm{m}\end{array}$} & VNS & 12 & 260 & 12.27 & $8.9005 \cdot 10^{4}$ & $7.3328 \cdot 10^{4}$ \\
\hline & MA & 12 & 496 & 12.02 & $9.0984 \cdot 10^{4}$ & $8.7607 \cdot 10^{4}$ \\
\hline & AG & 12 & 4 & 18.9467 & $8.5403 \cdot 10^{4}$ & $8.4764 \cdot 10^{3}$ \\
\hline & SA & 16 & 3 & 26.456 & $4.0543 \cdot 10^{3}$ & 30.7819 \\
\hline & TS & 12 & 1 & 15.9200 & $1.7488 \cdot 10^{4}$ & $6.1199 \cdot 10^{2}$ \\
\hline \multirow{5}{*}{$\begin{array}{l}N_{x}: 500.000 \mathrm{~N} / \mathrm{m} \\
N_{y}: 1.000 .000 \mathrm{~N} / \mathrm{m}\end{array}$} & VNS & 12 & 15 & 13.96 & $3.6897 \cdot 10^{4}$ & $1.3575 \cdot 10^{4}$ \\
\hline & MA & 12 & 98 & 13.61 & $3.6897 \cdot 10^{4}$ & $1.8147 \cdot 10^{4}$ \\
\hline & AG & 14 & 1 & 23.1267 & $1.1361 \cdot 10^{4}$ & $1.146 \cdot 10^{3}$ \\
\hline & SA & 16 & 3 & 31.672 & $5.6763 \cdot 10^{3}$ & 22.3771 \\
\hline & TS & 14 & 3 & 17.5640 & $5.2902 \cdot 10^{3}$ & 81.8767 \\
\hline
\end{tabular}


TABle 7: Continued.

\begin{tabular}{|c|c|c|c|c|c|c|}
\hline Loads & Algorithm & $\mathrm{NL}_{\min }$ & NL & $\overline{\mathrm{NL}}$ & $\mathrm{FF}_{\max }$ & $\overline{\mathrm{FF}}$ \\
\hline \multirow{5}{*}{$\begin{array}{l}N_{x}: 500.000 \mathrm{~N} / \mathrm{m} \\
N_{y}: 1.250 .000 \mathrm{~N} / \mathrm{m}\end{array}$} & VNS & 12 & 72 & 14.28 & $2.9117 \cdot 10^{4}$ & $8.6122 \cdot 10^{3}$ \\
\hline & MA & 12 & 339 & 12.81 & $2.9117 \cdot 10^{4}$ & $2.173 \cdot 10^{4}$ \\
\hline & $\mathrm{AG}$ & 16 & 2 & 27.4133 & $2.6399 \cdot 10^{3}$ & $2.2388 \cdot 10^{2}$ \\
\hline & SA & 18 & 2 & 35.388 & $1.23 \cdot 10^{3}$ & 4.4746 \\
\hline & TS & 16 & 1 & 19.2560 & $9.2541 \cdot 10^{2}$ & 23.4648 \\
\hline \multirow{5}{*}{$\begin{array}{l}N_{x}: 500.000 \mathrm{~N} / \mathrm{m} \\
N_{y}: 1.500 .000 \mathrm{~N} / \mathrm{m}\end{array}$} & VNS & 14 & 363 & 14.636 & $1.1324 \cdot 10^{4}$ & $5.3271 \cdot 10^{3}$ \\
\hline & MA & 14 & 494 & 14.02 & $1.1324 \cdot 10^{4}$ & $1.0644 \cdot 10^{4}$ \\
\hline & $\mathrm{AG}$ & 18 & 10 & 30.1067 & $8.7844 \cdot 10^{2}$ & 85.4087 \\
\hline & SA & 16 & 2 & 38.476 & $9.3088 \cdot 10^{2}$ & 4.1987 \\
\hline & TS & 16 & 1 & 20.3560 & $8.7751 \cdot 10^{2}$ & 18.3449 \\
\hline \multirow{5}{*}{$\begin{array}{l}N_{x}: 750.000 \mathrm{~N} / \mathrm{m} \\
N_{y}: 750.000 \mathrm{~N} / \mathrm{m}\end{array}$} & VNS & 16 & 500 & 16 & $3.522 \cdot 10^{3}$ & $3.3743 \cdot 10^{3}$ \\
\hline & MA & 16 & 500 & 16 & $3.522 \cdot 10^{3}$ & $3.522 \cdot 10^{3}$ \\
\hline & AG & 16 & 15 & 22.7667 & $3.522 \cdot 10^{3}$ & $7.5575 \cdot 10^{2}$ \\
\hline & SA & 16 & 2 & 29.65 & $3.1351 \cdot 10^{3}$ & 18.3958 \\
\hline & TS & 16 & 16 & 18.9880 & $3.5220 \cdot 10^{3}$ & $1.4030 \cdot 10^{2}$ \\
\hline \multirow{5}{*}{$\begin{array}{l}N_{x}: 750.000 \mathrm{~N} / \mathrm{m} \\
N_{y}: 1.000 .000 \mathrm{~N} / \mathrm{m}\end{array}$} & VNS & 18 & 500 & 18 & $1.0035 \cdot 10^{3}$ & $9.2486 \cdot 10^{2}$ \\
\hline & MA & 18 & 500 & 18 & $1.0073 \cdot 10^{3}$ & $9.8167 \cdot 10^{2}$ \\
\hline & $\mathrm{AG}$ & 18 & 16 & 27.4133 & $9.7849 \cdot 10^{2}$ & $1.8292 \cdot 10^{2}$ \\
\hline & SA & 20 & 4 & 35.736 & $3.3870 \cdot 10^{2}$ & 2.003 \\
\hline & TS & 18 & 9 & 21.4320 & $8.8434 \cdot 10^{2}$ & 24.9275 \\
\hline \multirow{5}{*}{$\begin{array}{l}N_{x}: 750.000 \mathrm{~N} / \mathrm{m} \\
N_{y}: 1.250 .000 \mathrm{~N} / \mathrm{m}\end{array}$} & VNS & 18 & 38 & 19.848 & $5.2267 \cdot 10^{2}$ & $3.1132 \cdot 10^{2}$ \\
\hline & MA & 16 & 7 & 18.49 & $5.2345 \cdot 10^{2}$ & $4.3804 \cdot 10^{2}$ \\
\hline & $\mathrm{AG}$ & 20 & 10 & 30.52 & $3.2510 \cdot 10^{2}$ & 54.4953 \\
\hline & SA & 20 & 2 & 40.38 & $1.8789 \cdot 10^{2}$ & 1.3868 \\
\hline & TS & 20 & 2 & 23.7400 & $1.9273 \cdot 10^{2}$ & 2.8100 \\
\hline \multirow{5}{*}{$\begin{array}{l}N_{x}: 750.000 \mathrm{~N} / \mathrm{m} \\
N_{y}: 1.500 .000 \mathrm{~N} / \mathrm{m}\end{array}$} & VNS & 18 & 11 & 20.708 & $3.3956 \cdot 10^{2}$ & $1.4176 \cdot 10^{2}$ \\
\hline & MA & 18 & 63 & 19.776 & $3.3956 \cdot 10^{2}$ & $1.9003 \cdot 10^{2}$ \\
\hline & AG & 22 & 16 & 34.3 & $1.0962 \cdot 10^{2}$ & 16.2374 \\
\hline & SA & 26 & 1 & 45.928 & 5.8144 & 0.032 \\
\hline & TS & 22 & 3 & 25.8480 & 43.3493 & 0.7962 \\
\hline \multirow{5}{*}{$\begin{array}{l}N_{x}: 1.000 .000 \mathrm{~N} / \mathrm{m} \\
N_{y}: 1.000 .000 \mathrm{~N} / \mathrm{m}\end{array}$} & VNS & 20 & 500 & 20 & $3.2888 \cdot 10^{2}$ & $3.1014 \cdot 10^{2}$ \\
\hline & MA & 20 & 500 & 20 & $3.2888 \cdot 10^{2}$ & $3.2887 \cdot 10^{2}$ \\
\hline & $\mathrm{AG}$ & 20 & 5 & 30.44 & $2.9623 \cdot 10^{2}$ & 44.4987 \\
\hline & SA & 20 & 2 & 38.96 & $2.2611 \cdot 10^{2}$ & 1.8568 \\
\hline & TS & 20 & 1 & 24.3960 & $1.9686 \cdot 10^{2}$ & 5.8882 \\
\hline \multirow{5}{*}{$\begin{array}{l}N_{x}: 1.000 .000 \mathrm{~N} / \mathrm{m} \\
N_{y}: 1.250 .000 \mathrm{~N} / \mathrm{m}\end{array}$} & VNS & 22 & 500 & 22 & $1.1748 \cdot 10^{2}$ & $1.0838 \cdot 10^{2}$ \\
\hline & MA & 22 & 500 & 22 & $1.1785 \cdot 10^{2}$ & $1.1536 \cdot 10^{2}$ \\
\hline & $\mathrm{AG}$ & 22 & 9 & 34.2467 & $1.1539 \cdot 10^{2}$ & 12.4818 \\
\hline & SA & 26 & 3 & 44.54 & 22.4217 & 0.1669 \\
\hline & TS & 22 & 3 & 26.7880 & $1.0333 \cdot 10^{2}$ & 1.7983 \\
\hline \multirow{5}{*}{$\begin{array}{l}N_{x}: 1.000 .000 \mathrm{~N} / \mathrm{m} \\
N_{y}: 1.500 .000 \mathrm{~N} / \mathrm{m}\end{array}$} & VNS & 24 & 500 & 24 & 46.2995 & 42.4606 \\
\hline & MA & 24 & 500 & 24 & 46.4240 & 45.1922 \\
\hline & AG & 24 & 8 & 37.9467 & 44.3415 & 4.5575 \\
\hline & SA & 28 & 7 & 49.4 & 13.0737 & 0.165 \\
\hline & TS & 24 & 1 & 29.6360 & 19.4564 & 0.2810 \\
\hline
\end{tabular}


TABLe 7: Continued.

\begin{tabular}{|c|c|c|c|c|c|c|}
\hline Loads & Algorithm & $\mathrm{NL}_{\min }$ & $\mathrm{NL}$ & $\overline{\mathrm{NL}}$ & $\mathrm{FF}_{\max }$ & $\overline{\mathrm{FF}}$ \\
\hline \multirow{5}{*}{$\begin{array}{l}N_{x}: 1.250 .000 \mathrm{~N} / \mathrm{m} \\
N_{y}: 1.250 .000 \mathrm{~N} / \mathrm{m}\end{array}$} & VNS & 24 & 469 & 24.124 & 46.643 & 41.4749 \\
\hline & MA & 24 & 500 & 24 & 46.643 & 46.6245 \\
\hline & $\mathrm{AG}$ & 24 & 3 & 37.0533 & 42.1974 & 4.8935 \\
\hline & SA & 26 & 1 & 46.908 & 13.6039 & 0.0983 \\
\hline & TS & 26 & 10 & 29.3760 & 15.1788 & 0.7773 \\
\hline \multirow{5}{*}{$\begin{array}{l}N_{x}: 1.250 .000 \mathrm{~N} / \mathrm{m} \\
N_{y}: 1.500 .000 \mathrm{~N} / \mathrm{m}\end{array}$} & VNS & 26 & 130 & 27.496 & 9.8711 & 7.8726 \\
\hline & MA & 26 & 231 & 27.144 & 10.1457 & 8.3843 \\
\hline & $\mathrm{AG}$ & 28 & 16 & 40.2333 & 7.8922 & 1.6101 \\
\hline & SA & 30 & 2 & 52.46 & 4.6966 & 0.0335 \\
\hline & TS & 28 & 7 & 32.5520 & 7.0430 & 0.2389 \\
\hline \multirow{5}{*}{$\begin{array}{l}N_{x}: 1.500 .000 \mathrm{~N} / \mathrm{m} \\
N_{y}: 1.500 .000 \mathrm{~N} / \mathrm{m}\end{array}$} & VNS & 30 & 500 & 30 & 3.8763 & 3.5545 \\
\hline & MA & 30 & 500 & 30 & 3.8763 & 3.8245 \\
\hline & $A G$ & 30 & 10 & 42.86 & 3.7687 & 0.6741 \\
\hline & SA & 30 & 1 & 54.748 & 3.1197 & 0.015 \\
\hline & TS & 38 & 8 & 35.3000 & 2.3280 & 0.1268 \\
\hline
\end{tabular}

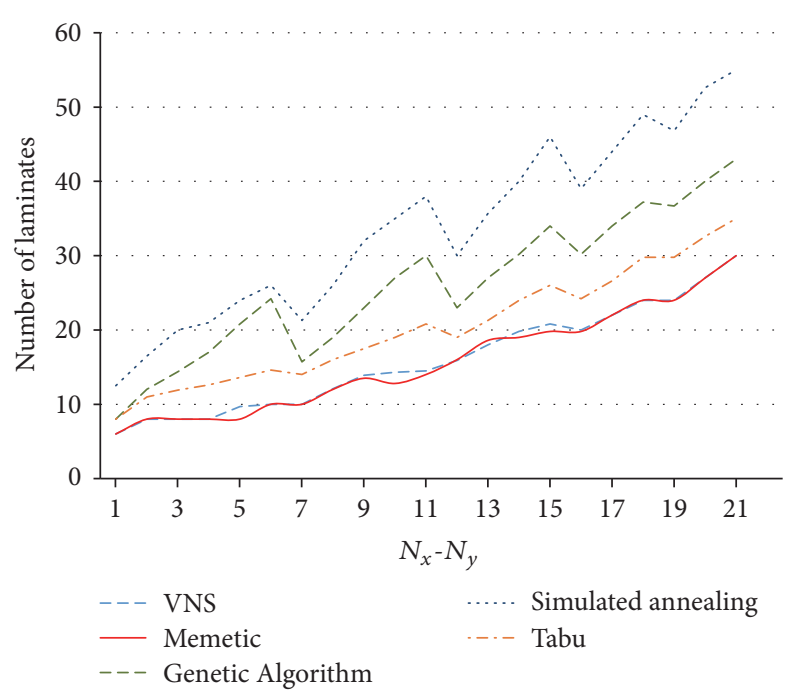

\begin{tabular}{lcc}
\hline Abscissa & $N_{x}(\mathrm{~N} / \mathrm{m})$ & $N_{y}(\mathrm{~N} / \mathrm{m})$ \\
\hline 1 & 250.000 & 250.000 \\
2 & 250.000 & 500.000 \\
3 & 250.000 & 750.000 \\
4 & 250.000 & 1.000 .000 \\
5 & 250.000 & 1.250 .000 \\
6 & 250.000 & 1.500 .000 \\
7 & 500.000 & 500.000 \\
8 & 500.000 & 750.000 \\
9 & 500.000 & 1.000 .000 \\
10 & 500.000 & 1.250 .000 \\
11 & 500.000 & 1.500 .000 \\
12 & 750.000 & 750.000 \\
13 & 750.000 & 1.000 .000 \\
14 & 750.000 & 1.250 .000 \\
15 & 750.000 & 1.500 .000 \\
16 & 1.000 .000 & 1.000 .000 \\
17 & 1.000 .000 & 1.250 .000 \\
18 & 1.000 .000 & 1.500 .000 \\
19 & 1.250 .000 & 1.250 .000 \\
20 & 1.250 .000 & 1.500 .000 \\
21 & 1.500 .000 & 1.500 .000 \\
\hline
\end{tabular}

FIgURE 5: Average number of layers for the different algorithms.

TABLE 8: Average rankings of algorithms achieved by Friedman test.

\begin{tabular}{lc}
\hline Algorithm & Average rankings \\
\hline MA & 1 \\
VNS & 2 \\
GA & 3 \\
TS & 4.095 \\
SA & 4.948 \\
\hline
\end{tabular}

solutions obtained by the others heuristics (see Table 7). Figure 5 shows the average number of laminas corresponding to the laminates obtained with all heuristics.
As an example of results, in Table 10 are shown the specifications of the best laminate obtained with the 5 heuristics in the loading case $N_{x}=1.000 .000 \mathrm{~N} / \mathrm{m}, N_{y}=1.500 .000 \mathrm{~N} / \mathrm{m}$.

Finally, Figure 6 shows graphically the different coefficients ( $P_{k}^{i}$ or Tsai-Wu, $P_{1}, P_{2}$, and $P_{12}$ ) corresponding to the laminas of the best laminate obtained with the MA-based model in the loading case shown in Table 10. In this case, a large degree of uniformity of the coefficients $P_{k}^{i}$ around 1 can be observed. It indicates an excellent exploitation of all the laminas.

\section{Application to Specific Cases}

Previously, the proposed model has been applied to general cases. In this section, the proposed model is applied to two 

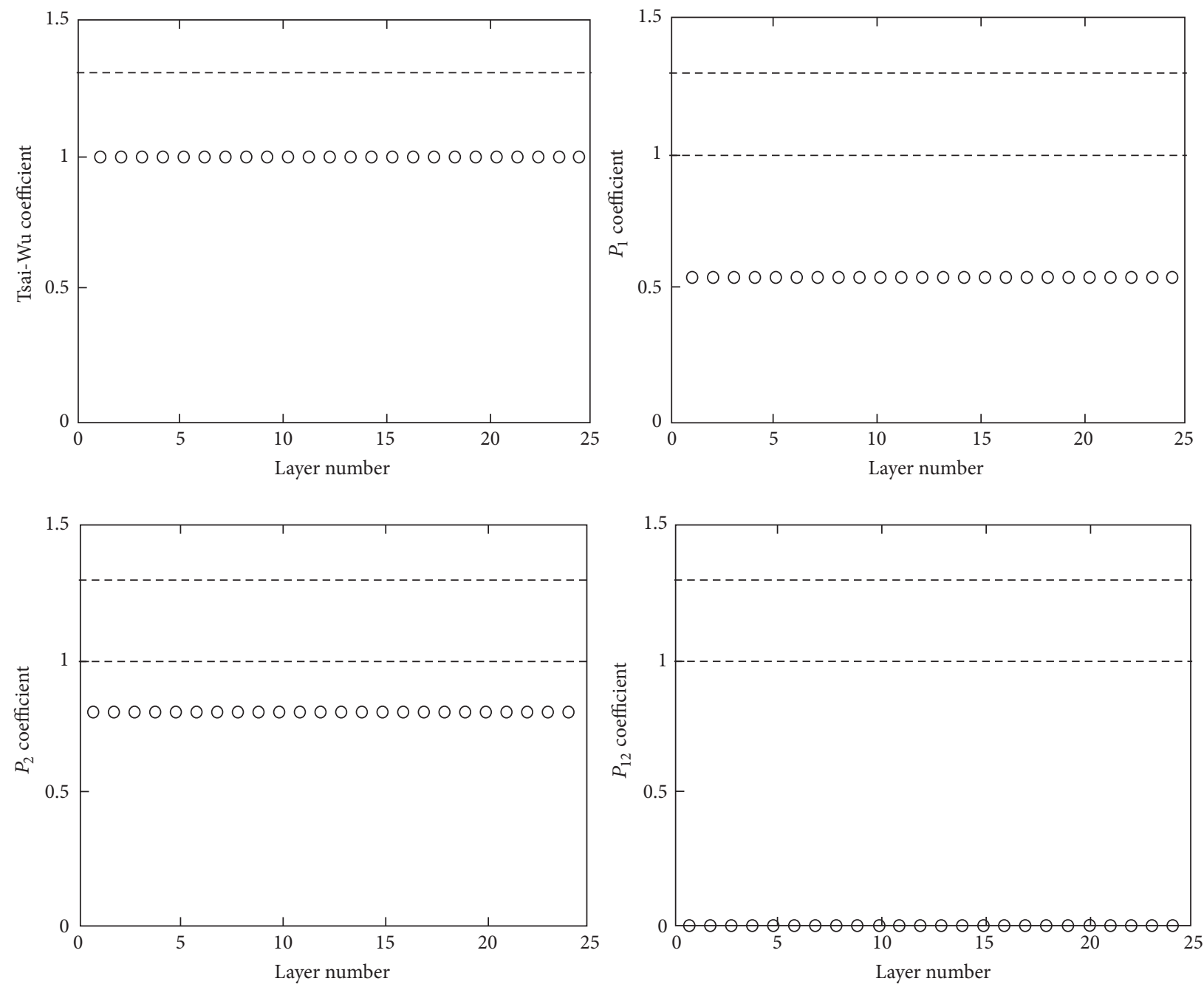

Figure 6: Coefficients $P_{k}^{i}$ (Tsai-Wu), $P_{1}, P_{2}$, and $P_{12}$ of each laminate in the best laminate obtained by the MA-based model.

TABLE 9: $p$ values for Nemenyi test.

\begin{tabular}{lc}
\hline Hypothesis & $p_{\text {Nemenyi }}$ \\
\hline MA vs. SA & 0 \\
MA vs. TS & 0 \\
VNS vs. SA & 0 \\
VNS vs. TS & 0.000018 \\
MA vs. GA & 0.000042 \\
GA vs. SA & 0.000095 \\
GA vs. TS & 0.024796 \\
MA vs. VNS & 0.040424 \\
VNS vs. GA & 0.040424 \\
SA vs. TS & 0.097110 \\
\hline
\end{tabular}

significant specific cases comparing the results with another author's solution.

5.1. Minimum Thickness Design. Le Riche and Haftka [26] developed a GA for minimum thickness composite laminate design. They consider a graphite-epoxy plate with the load case with $N_{x}=12.500 \mathrm{lb} /$ in $=2.189 .956 \mathrm{~N} / \mathrm{m}$ and $N_{y}=$ $3.125 \mathrm{lb} /$ in $=547.890 \mathrm{~N} / \mathrm{m}$. The characteristics of the best laminated obtained by authors are shown in Table 11.

The laminate provided by the MA proposed model, under the same load case, is shown in Table 12.

5.2. Stacking Sequence Design. Liu et al. [54] developed a permutation GA for stacking sequence design of composite laminates. They consider a graphite-epoxy laminate with the load case with $N_{x}=-10.000 \mathrm{lb} /$ in $=-1.751 .965 \mathrm{~N} / \mathrm{m}$ and $N_{y}=-2.000 \mathrm{lb} /$ in $=-350.393 \mathrm{~N} / \mathrm{m} ; N_{x y}=1.000 \mathrm{lb} / \mathrm{in}=$ $175.197 \mathrm{~N} / \mathrm{m}$. The characteristics of the best laminated obtained by authors are shown in Table 13 .

The laminate provided by the MA proposed model, under the same load case, is shown in Table 14.

The laminate represented in Tables 12 and 14 has been validated using a finite elements simulation software. To do so we employed the ANSYS 17.0 software package; additionally, the SHELL281 was used as the element of validation code, maintaining the same conditions and loadings when possible, and its characteristics can be consulted in [78]. 
TABLE 10: Characteristics of the best laminate obtained with each algorithm.

\begin{tabular}{|c|c|c|c|c|c|c|}
\hline Algorithm & Fiber & Matrix & $V_{f}$ & Fitness & Stacking sequence & Thickness (mm) \\
\hline MA & P-100 & Peek & 0.40 & 46.424 & 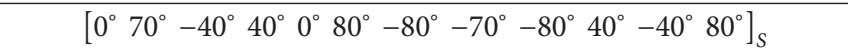 & 4.32 \\
\hline VNS & P-100 & Peek & 0.40 & 46.229 & 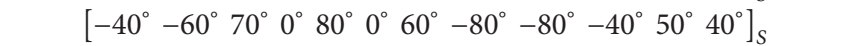 & 4.32 \\
\hline GA & P-100 & Peek & 0.40 & 44.341 & 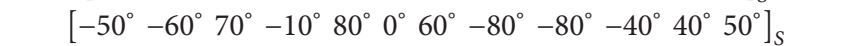 & 4.32 \\
\hline SA & P-100 & Peek & 0.30 & 13.073 & 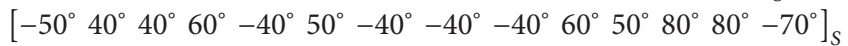 & 5.04 \\
\hline $\mathrm{TA}$ & P-100 & Peek & 0.40 & 19.456 & {$\left[50^{\circ}-40^{\circ}-50^{\circ}-40^{\circ} 50^{\circ} 50^{\circ} 60^{\circ}-60^{\circ}-60^{\circ} 50^{\circ} 50^{\circ}-50^{\circ}\right]_{S}$} & 4.32 \\
\hline
\end{tabular}

TABLE 11: Characteristics of the best laminate obtained by Le Riche and Haftka's GA.

\begin{tabular}{lc}
\hline Characteristic & Value \\
\hline Stacking sequence & {$\left[ \pm 45_{2} / 90_{2} / \pm 45_{3} / 0_{2} / \pm 45 / 0_{4} / \pm 45 / 0_{2}\right]_{s}$} \\
$\mathrm{~N}^{\circ}$ of Laminas & 48 \\
Laminate thickness & $0.240 \mathrm{in}=6.096 \mathrm{~mm}$ \\
$\mathrm{FF}_{\max }$ & 38.002 \\
\hline
\end{tabular}

TABLE 12: Characteristics of the best laminate obtained by the MA proposed model.

\begin{tabular}{lc}
\hline Characteristic & Value \\
\hline Stacking sequence & {$\left[30_{4} /-20_{2} /-30_{4} / 20_{2} / 30_{2} /-30_{2}\right]_{s}$} \\
Number of laminas & 32 \\
Laminate thickness & 0.234 in $=5.94 \mathrm{~mm}$ \\
$\mathrm{FF}_{\max }$ & 42.001 \\
\hline
\end{tabular}

TABLE 13: Characteristics of the best laminate obtained by Liu et al. permutation GA.

\begin{tabular}{lc}
\hline Characteristic & Value \\
\hline Stacking Sequence & {$\left[0_{7} / 45_{15} / 90_{7}\right]_{s}$} \\
$\mathrm{~N}^{\circ}$ of Laminas & 58 \\
Laminate Thickness & $0.290 \mathrm{in}=7.366 \mathrm{~mm}$ \\
$\mathrm{FF}_{\max }$ & 29.002 \\
\hline
\end{tabular}

TABLE 14: Characteristics of the best laminate obtained with the MA proposed model.

\begin{tabular}{lc}
\hline Characteristic & Value \\
\hline Stacking Sequence & {$\left[0_{4} /-40_{3} / 10_{3} / 0_{4} /-40_{3} / 0\right]_{s}$} \\
$\mathrm{~N}^{\circ}$ of Laminas & 42 \\
Laminate Thickness & $0.275 \mathrm{in}=6.985 \mathrm{~mm}$ \\
$\mathrm{FF}_{\max }$ & 40.010 \\
\hline
\end{tabular}

\section{Conclusions}

In this paper, we have shown that the use of techniques based on systematic exploitation of knowledge of the problem, together with the combination of metaheuristics based on population as well as in local search, offers more effective and dynamic methods for the solution of laminated polymers design. To this end, a study of the main techniques used in the design of laminated polymers was firstly performed, in order to carry out a comparative analysis.
A Memetic Computing-based model has been presented for the design of Symmetric Laminated Composites and Structures. This model implements a general encoding for the design of composites and a fitness function that has taken into account economic and safety criteria in design. Also, a dynamic reproductive operator is presented, in which the classic crossover operator is modified in order to improve the dynamics in the change of the number of layers.

Finally, a set of local search operators are implemented. These allow a lamina to be added or removed, to change its orientation, type of matrix, type of fiber, or volume fraction. Two new operators have been defined and added to the set to improve the exploitation of the solutions in the region of the search space.

The proposed Memetic Computing model has been subjected to a broad analysis and applied in two specific cases. Firstly, the model has been applied to the design of a plate under distributed $N_{x}$ and $N_{y}$ loading, and the results have been compared with those obtained by other well-known design methods. In most cases, the minimum number and average number of laminas are lesser. Also, the proposed model has been compared with two significant models found in the literature, obtaining comparable results. These results show that the proposed model is a general and flexible design method for Symmetric Laminated Composites and Structures. We consider that these results can be applied to real-life scenarios with a high reliability. Finally, all solutions obtained by the MA proposed model in Sections 5.1 and 5.2 have been validated by the ANSYS software package using the same conditions and load system.

\section{Conflicts of Interest}

The authors declare that there are no conflicts of interest regarding the publication of this paper.

\section{Acknowledgments}

This work was partially supported by the Department of Research, Area of Publications, Critical Mass and Patents of the University of Guayaquil, Ecuador.

\section{References}

[1] M. Kashtalyan, Introduction to Composite Materials Design, vol. 115, CRC Press, Boca Raton, Fla, USA, 2nd edition, 2010.

[2] Z. Gürdal, R. T. Haftka, P. Hajela, and Z. Gürdal, Design and Optimization of Laminated Composite Materials, John Wiley and Sons, 1999. 
[3] L. Grosset, R. LeRiche, and R. T. Haftka, "A double-distribution statistical algorithm for composite laminate optimization," Structural and Multidisciplinary Optimization, vol. 31, no. 1, pp. 49-59, 2006.

[4] J. Huang and R. T. Haftka, "Optimization of fiber orientations near a hole for increased load-carrying capacity of composite laminates," Structural and Multidisciplinary Optimization, vol. 30, no. 5, pp. 335-341, 2005.

[5] F. L. Matthews, G. A. O. Davies, D. Hitchings, and C. Soutis, Finite Element Modelling of Composite Materials and Structures, Woodhead Publishing Limited, 2000.

[6] T. J. Lenz, Designing Composite Material Systems Using Generic Tasks and Case-based Reasoning, Michigan State University, 1997.

[7] D. B. Adams, L. T. Watson, and Z. Gürdal, "Optimization and blending of composite laminates using genetic algorithms with migration," Mechanics of Advanced Materials and Structures, vol. 10, no. 3, pp. 183-203, 2003.

[8] E. Falkenauer, Genetic Algorithms and Grouping Problems, John Wiley and Sons, New York, NY, USA, 1998.

[9] G. Soremekun, Z. Gürdal, R. T. Haftka, and L. T. Watson, "Composite laminate design optimization by genetic algorithm with generalized elitist selection," Computers and Structures, vol. 79, no. 2, pp. 131-143, 2001.

[10] N. Kogiso, L. T. Watson, Z. Gürdal, and R. T. Haftka, "Genetic algorithms with local improvement for composite laminate design," Structural Optimization, vol. 7, no. 4, pp. 207-218, 1994.

[11] M. T. Mcmahon and L. T. Watson, "A distributed genetic algorithm with migration for the design of composite laminate structures," Parallel Algorithms and Applications, vol. 14, no. 4, pp. 329-362, 2000.

[12] S. Rajeev and C. S. Krishnamoorthy, "Discrete optimization of structures using genetic algorithms," Journal of Structural Engineering, vol. 118, no. 5, pp. 1233-1250, 1992.

[13] K. Yamazaki, "Two-level optimization technique of composite laminate panels by genetic algorithms," in Proceedings of the 37th AIAA/ASME/ASCE/AHS/ASC Structure, Structural Dynamics and Materials Conference, 1996, pp. 1882-1887, usa, April 1996.

[14] N. Pai, A. Kaw, and M. Weng, "Optimization of laminate stacking sequence for failure load maximization using Tabu search," Composites Part B: Engineering, vol. 34, no. 4, pp. 405413, 2003.

[15] Y. Hirano and A. Todoroki, "Stacking sequence optimizations for composite laminates using fractal branch and bound method: Application for supersonic panel flutter problem with buckling load condition," Advanced Composite Materials: The Official Journal of the Japan Society of Composite Materials, vol. 13, no. 2, pp. 89-106, 2004.

[16] T.-U. Kim and H.-C. Sin, "Optimal design of composite laminated plates with the discreteness in ply angles and uncertainty in material properties considered," Computers and Structures, vol. 79, no. 29-30, pp. 2501-2509, 2001.

[17] R. Dawkins, The Selfish Gene: 30th Anniversary Edition, OUP Oxford, Oxford, USA, 2006.

[18] P. Moscato and C. Cotta Porras, "An introduction to memetic algorithms," Inteligencia Artificial: Revista Iberoamericana de Inteligencia Artificial, vol. 7, no. 19, pp. 131-148, 2003.

[19] C. Cotta, "Memetic algorithms with partial Lamarckism for the shortest common supersequence problem," Lecture Notes in Computer Science, vol. 3562, pp. 84-91, 2005.
[20] M. Gen, "Parallel machine scheduling problems using memetic algorithms," Computers and Industrial Engineering, vol. 33, pp. 761-764, 1997.

[21] Buriol, L. S., M. G. C. Resende, C. C. Ribeiro and M. Thorup. 2002. "A Memetic Algorithm for OSPF Routing." Proceedings of the sixth INFORMS Conference on Telecommunications, Boca Raton, Florida, 187-188.

[22] M. Pastorino, S. Caorsi, A. Massa, and A. Randazzo, "Reconstruction algorithms for electromagnetic imaging," IEEE Transactions on Instrumentation and Measurement, vol. 53, no. 3, pp. 692-699, 2004.

[23] Venkataraman, S. and R. T. Haftka. 1995. "Optimization of composite panels - a review." Proceedings of the American society of composites-14th annual technical conference. Fairborn. $\mathrm{OH}$. 479-488.

[24] K. J. Callahan and G. E. Weeks, "Optimum design of composite laminates using genetic algorithms," Composites Engineering, vol. 2, no. 3, pp. 149-160, 1992.

[25] S. Nagendra, R. T. Haftka, and Z. Gürdal, "Stacking sequence optimization of simply supported laminates with stability and strain constraints," AIAA Journal, vol. 30, no. 8, pp. 2132-2137, 1992.

[26] R. Le Riche and R. T. Haftka, "Improved genetic algorithm for minimum thickness composite laminate design," Composites Engineering, vol. 5, no. 2, pp. 143-161, 1995.

[27] N. R. Ball, P. M. Sargent, and D. O. Ige, "Genetic algorithm representations for laminate layups," Artificial Intelligence in Engineering, vol. 8, no. 2, pp. 99-108, 1993.

[28] R. Le Riche and R. T. Haftka, "Optimization of laminate stacking sequence for buckling load maximization by genetic algorithm," AIAA journal, vol. 31, no. 5, pp. 951-956, 1993.

[29] J. H. Park, J. H. Hwang, C. S. Lee, and W. Hwang, "Stacking sequence design of composite laminates for maximum strength using genetic algorithms," Composite Structures, vol. 52, no. 2, pp. 217-231, 2001.

[30] N. Kogiso, L. T. Watson, Z. GÜrdal, R. T. Haftka, and S. Nagendra, "Design of composite laminates by a genetic algorithm with memory," Mechanics of Composite Materials and Structures, vol. 1, no. 1, pp. 95-117, 1994.

[31] A. Todoroki, "Stacking sequence matching by two-stage genetic algorithm with consanguineous initial population," in Proceedings of the 38th AIAA/ASME/ASCE/AHS/ASC structures, structural dynamics and materials conference, pp. 1297-1302, Kissimmee, FL, USA, April 1997.

[32] T. Messager, M. Pyrz, B. Gineste, and P. Chauchot, "Optimal laminations of thin underwater composite cylindrical vessels," Composite Structures, vol. 58, no. 4, pp. 529-537, 2002.

[33] A. Todoroki and T. Ishikawa, "Design of experiments for stacking sequence optimizations with genetic algorithm using response surface approximation," Composite Structures, vol. 64, no. 3-4, pp. 349-357, 2004.

[34] M. Abouhamze and M. Shakeri, "Multi-objective stacking sequence optimization of laminated cylindrical panels using a genetic algorithm and neural networks," Composite Structures, vol. 81, no. 2, pp. 253-263, 2007.

[35] R. Le Riche and J. Gaudin, "Design of dimensionally stable composites by evolutionary optimization," Composite Structures, vol. 41, no. 2, pp. 97-111, 1998.

[36] E. Potgieter and N. Stander, "The genetic algorithm applied to stiffness maximization of laminated plates: Review and comparison," Structural Optimization, vol. 15, no. 3-4, pp. 221229, 1998. 
[37] I. Rajendran and S. Vijayarangan, "Optimal design of a composite leaf spring using genetic algorithms," Computers and Structures, vol. 79, no. 11, pp. 1121-1129, 2001.

[38] G. Narayana Naik, S. Gopalakrishnan, and R. Ganguli, “Design optimization of composites using genetic algorithms and failure mechanism based failure criterion," Composite Structures, vol. 83, no. 4, pp. 354-367, 2008.

[39] A. Todoroki, K. Watanabe, and H. Kobayashi, "Application of genetic algorithms to stiffness optimization of laminated composite plates with stress-concentrated open holes," JSME International Journal, Series A: Mechanics and Material Engineering, vol. 38, no. 4, pp. 458-464, 1995.

[40] K. Sivakumar, N. G. R. Iyengar, and K. Deb, “Optimum design of laminated composite plates with cutouts using a genetic algorithm," Composite Structures, vol. 42, no. 3, pp. 265-279, 1998.

[41] R. T. Haftka and Z. Gürdal, Elements of Structural Optimization, Kluwer Academic Publishers, Dordrecht, The Netherlands, 1992.

[42] M. Kemal Apalak, M. Yildirim, and R. Ekici, "Layer optimisation for maximum fundamental frequency of laminated composite plates for different edge conditions," Composites Science and Technology, vol. 68, no. 2, pp. 537-550, 2008.

[43] M. Walker and R. E. Smith, "A technique for the multiobjective optimisation of laminated composite structures using genetic algorithms and finite element analysis," Composite Structures, vol. 62, no. 1, pp. 123-128, 2003.

[44] A. Todoroki and R. T. Haftka, "Stacking sequence optimization by a genetic algorithm with a new recessive gene like repair strategy," Composites Part B: Engineering, vol. 29, no. 3, pp. 277285, 1998.

[45] C.-C. Lin and Y.-J. Lee, "Stacking sequence optimization of laminated composite structures using genetic algorithm with local improvement," Composite Structures, vol. 63, no. 3-4, pp. 339-345, 2004.

[46] S. Nagendra, D. Jestin, Z. Gürdal, R. T. Haftka, and L. T. Watson, "Improved genetic algorithm for the design of stiffened composite panels," Computers and Structures, vol. 58, no. 3, pp. 543-555, 1996.

[47] V. Kradinov, E. Madenci, and D. R. Ambur, "Application of genetic algorithm for optimum design of bolted composite lap joints," Composite Structures, vol. 77, no. 2, pp. 148-159, 2007.

[48] A. Muc and W. Gurba, "Genetic algorithms and finite element analysis in optimization of composite structures," Composite Structures, vol. 54, no. 2-3, pp. 275-281, 2001.

[49] D. J. Deka, G. Sandeep, D. Chakraborty, and A. Dutta, "Multiobjective optimization of laminated composites using finite element method and genetic algorithm," Journal of Reinforced Plastics and Composites, vol. 24, no. 3, pp. 273-285, 2005.

[50] C. H. Park, W. I. Lee, W. S. Han, and A. Vautrin, "Improved genetic algorithm for multidisciplinary optimization of composite laminates," Computers and Structures, vol. 86, no. 19-20, pp. 1894-1903, 2008.

[51] W. F. Punch III, R. C. Averill, E. D. Goodman, S.-C. Lin, Y. Ding, and Y. C. Yip, "Optimal design of laminated composite structures using coarse-grain parallel genetic algorithms," Computing Systems in Engineering, vol. 5, no. 4-6, pp. 415-423, 1994.

[52] P. Kere and J. Lento, "Design optimization of laminated composite structures using distributed grid resources," Composite Structures, vol. 71, no. 3-4, pp. 435-438, 2005.
[53] V. B. Gantovnik, Z. Gürdal, and L. T. Watson, "A genetic algorithm with memory for optimal design of laminated sandwich composite panels," Composite Structures, vol. 58, no. 4, pp. 513$520,2002$.

[54] B. Liu, R. T. Haftka, and M. A. Akgün, "Composite wing structural optimization using genetic algorithms and response surfaces," in Proceedings of the 7th AIAA/USAF/NASA/ISSMO Symposium on Multidisciplinary Analysis and Optimization, 1998, pp. 1-12, MO, USA, September 1998.

[55] C. A. Conceicao Antonio, "A hierarchical genetic algorithm with age structure for multimodal optimal design of hybrid composites," Structural and Multidisciplinary Optimization, vol. 31, no. 4, pp. 280-294, 2006.

[56] P. M. Sargent, D. O. Ige, and N. R. Ball, "Design of laminate composite layups using genetic algorithms," Engineering with Computers, vol. 11, no. 2, pp. 59-69, 1995.

[57] K. Sivakumar, N. G. R. Iyengar, and D. Kalyanmoy, "Optimization of composite laminates with cutouts using genetic algorithm, variable metric and complex search methods," Engineering Optimization, vol. 32, no. 5, pp. 635-657, 2000.

[58] A. Rama Mohan Rao and P. P. Shyju, "Development of a hybrid meta-heuristic algorithm for combinatorial optimisation and its application for optimal design of laminated composite cylindrical skirt," Computers and Structures, vol. 86, no. 7-8, pp. 796-815, 2008

[59] V. Savic, M. E. Tuttle, and Z. B. Zabinsky, "Optimization of composite I-sections using fiber angles as design variables," Composite Structures, vol. 53, no. 3, pp. 265-277, 2001.

[60] M. Lombardi, R. Haftka, and C. Cinquini, "Optimization of composite plates for buckling by simulated annealing," in Proceedings of 33rd AIAA/ASME/AHS structures, structural dynamics and materials conference, AIAA Paper 92-2314-CP, Dallas, TX, USA.

[61] D. Sadagopan and R. Pitchumani, "Application of genetic algorithms to optimal tailoring of composite materials," Composites Science and Technology, vol. 58, no. 3-4, pp. 571-589, 1998.

[62] A. C. Arvin and C. E. Bakis, "Optimal design of press-fitted filament wound composite flywheel rotors," Composite Structures, vol. 72, no. 1, pp. 47-57, 2006.

[63] H. E. Romeijn, Z. B. Zabinsky, D. L. Graesser, and S. Neogi, "New reflection generator for simulated annealing in mixedinteger/continuous global optimization," Journal of Optimization Theory and Applications, vol. 101, no. 2, pp. 403-427, 1999.

[64] O. Erdal and F. O. Sonmez, "Optimum design of composite laminates for maximum buckling load capacity using simulated annealing," Composite Structures, vol. 71, no. 1, pp. 45-52, 2005.

[65] K. Genovese, L. Lamberti, and C. Pappalettere, "Improved global-local simulated annealing formulation for solving nonsmooth engineering optimization problems," International Journal of Solids and Structures, vol. 42, no. 1, pp. 203-237, 2005.

[66] M. Di Sciuva, M. Gherlone, and D. Lomario, "Multiconstrained optimization of laminated and sandwich plates using evolutionary algorithms and higher-order plate theories," Composite Structures, vol. 59, no. 1, pp. 149-154, 2003.

[67] A. Rama Mohan Rao and N. Arvind, "Optimal stacking sequence design of laminate composite structures using tabu embedded simulated annealing," Structural Engineering and Mechanics, vol. 25, no. 2, pp. 239-268, 2007.

[68] A. Corz, J. A. Gomez-Ruiz, J. I. Pelaez, E. Tenorio, and J. Veintimilla, "Design and optimization of symmetric laminated composites using a variable neighbourhood search-based 
model," Engineering Optimization, vol. 44, no. 4, pp. 505-520, 2012.

[69] S. W. Tsai and E. M. Wu, "A general theory of strength for anisotropic materials," Journal of Composite Materials, vol. 5, pp. 58-80, 1971.

[70] J. Demšar, "Statistical comparisons of classifiers over multiple data sets," The Journal of Machine Learning Research, vol. 7, pp. 1-30, 2006.

[71] D. J. Sheskin, Handbook of Parametric and Nonparametric Statistical Procedures, Chapman and Hall/CRC, Boca Raton, Fla, USA, 5th edition, 2000.

[72] J. H. Zar, Biostatistical Analysis, Prentice Hall, 5th edition, 2009.

[73] M. Friedman, "The use of ranks to avoid the assumption of normality implicit in the analysis of variance," Journal of the American Statistical Association, vol. 32, no. 200, pp. 675-701, 1937.

[74] M. Friedman, "A comparison of alternative tests of significance for the problem of $\mathrm{m}$ rankings," The Annals of Mathematical Statistics, vol. 11, no. 1, pp. 86-92, 1940.

[75] R. Iman and J. Davenport, "Approximations of the critical region of the Friedman statistic," Communications in Statistics, vol. 9, pp. 571-595, 1980.

[76] J. Derrac, S. García, D. Molina, and F. Herrera, "A practical tutorial on the use of nonparametric statistical tests as a methodology for comparing evolutionary and swarm intelligence algorithms," Swarm and Evolutionary Computation, vol. 1, no. 1, pp. 3-18, 2011.

[77] P. B. Nemenyi, Distribution-Free Multiple Comparisons, Princeton University, 1963.

[78] Ansys Inc., 2016. Ansys Release 17.0. 


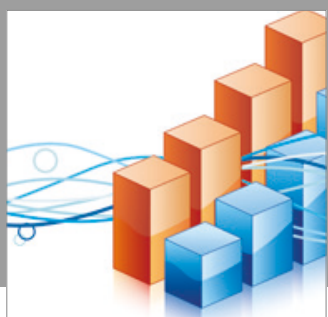

Advances in

Operations Research

vatersals

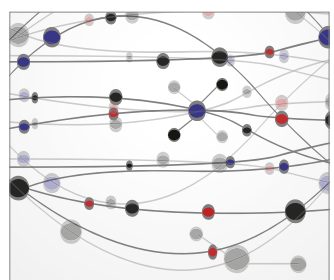

\section{The Scientific} World Journal
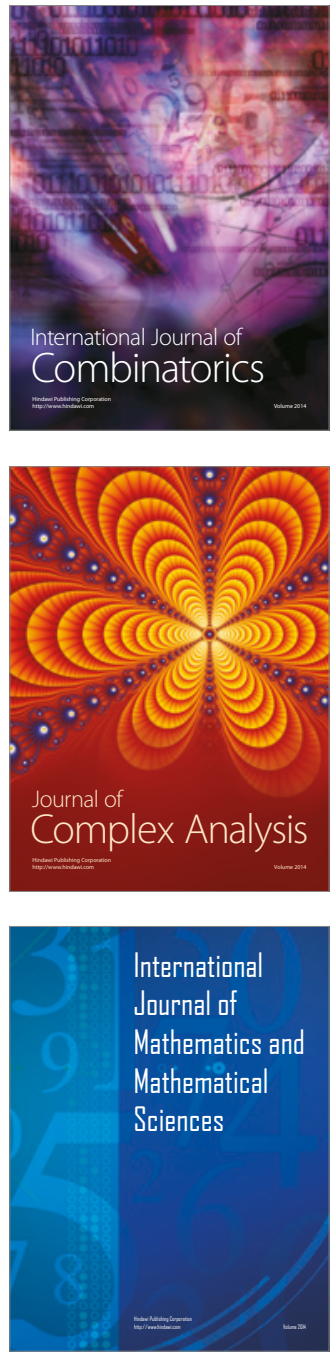
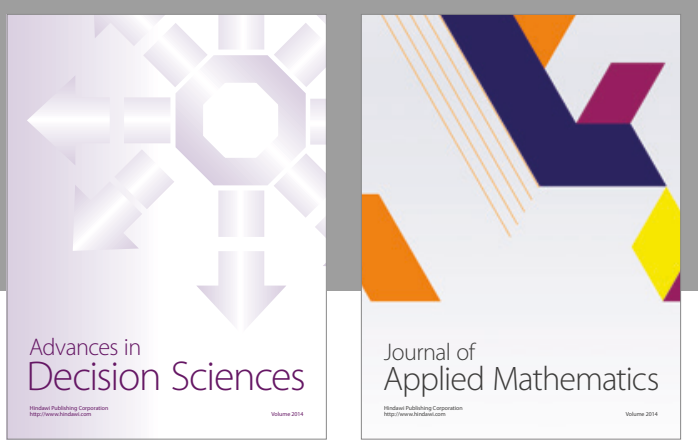

Algebra

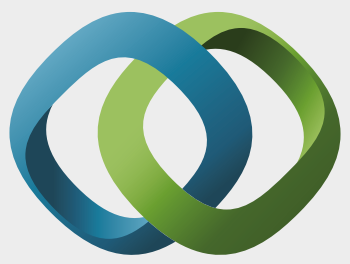

\section{Hindawi}

Submit your manuscripts at

https://www.hindawi.com
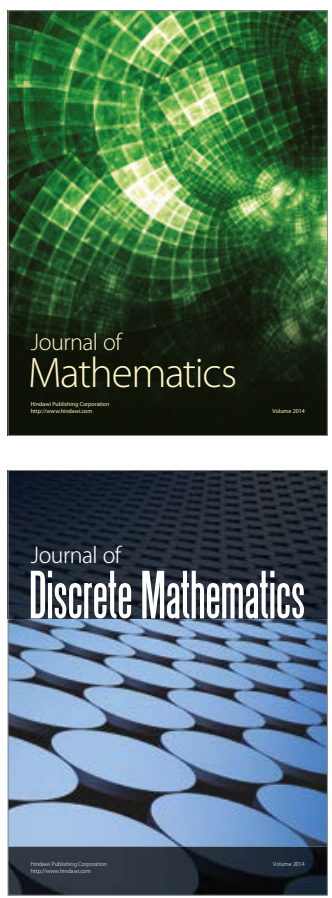

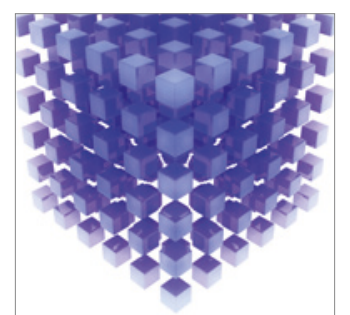

Mathematical Problems in Engineering
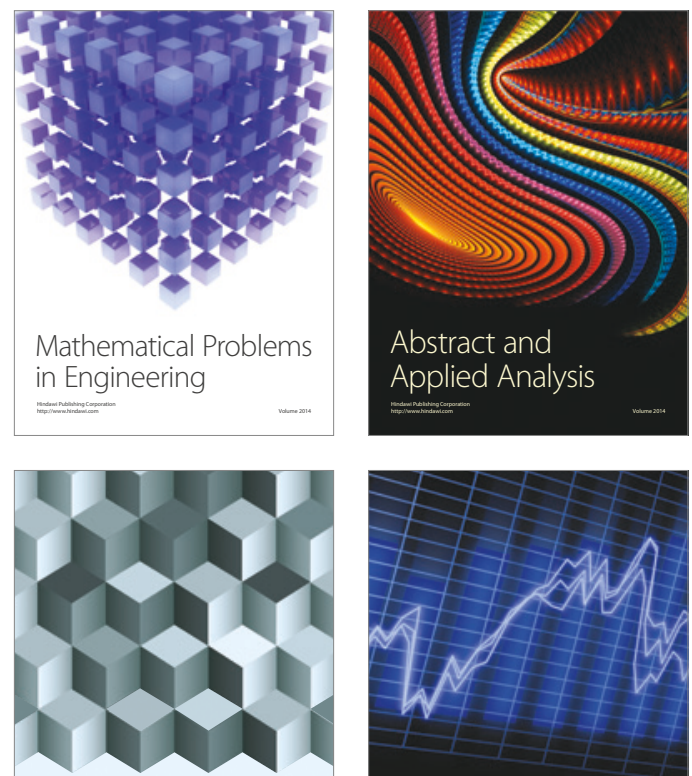

Journal of

Function Spaces

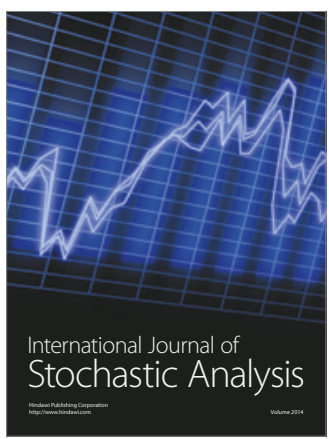

Probability and Statistics
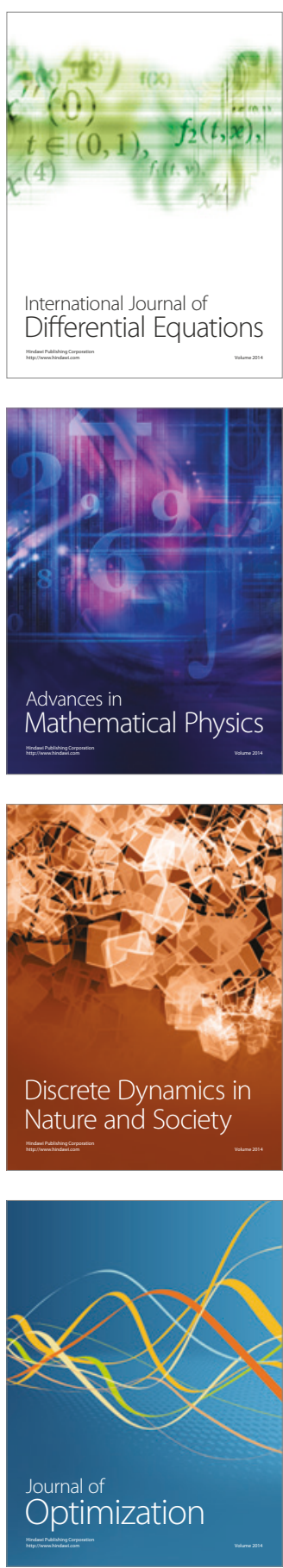